\title{
Association between Electronic Health Records and Health Care Utilization
}

\author{
R. Kaushal1,2,3,4,5,6; A. Edwards ${ }^{1,2,3}$; L.M. Kern",2,3,5; with the HITEC Investigators \\ ${ }^{1}$ Department of Healthcare Policy and Research, Weill Cornell Medical College, New York, NY.; \\ ${ }^{2}$ Health Information Technology Evaluation Collaborative, New York, NY.; \\ ${ }^{3}$ Center for Healthcare Informatics and Policy, Weill Cornell Medical College, New York, NY.; \\ ${ }^{4}$ Department of Pediatrics, Weill Cornell Medical College, New York, NY.; \\ ${ }^{5}$ Department of Medicine, Weill Cornell Medical College, New York, NY.; \\ ${ }^{6}$ New York-Presbyterian Hospital, New York, NY.
}

\section{Keywords}

Electronic health records, health services, health utilization, primary health care

\section{Summary}

Background: The federal government is investing approximately $\$ 20$ billion in electronic health records (EHRs), in part to address escalating health care costs. However, empirical evidence that provider use of EHRs decreases health care costs is limited.

Objective: To determine any association between EHRs and health care utilization.

Methods: We conducted a cohort study (2008-2009) in the Hudson Valley, a multi-payer, multiprovider community in New York State. We included 328 primary care physicians in predominantly small practices (median practice size four primary care physicians), who were caring for 223,772 patients. Data from an independent practice association was used to determine adoption of EHRs. Claims data aggregated across five commercial health plans was used to characterize seven types of health care utilization: primary care visits, specialist visits, radiology tests, laboratory tests, emergency department visits, hospital admissions, and readmissions. We used negative binomial regression to determine associations between EHR adoption and each utilization outcome, adjusting for ten physician characteristics.

Results: Approximately half (48\%) of the physicians were using paper records and half (52\%) were using EHRs. For every 100 patients seen by physicians using EHRs, there were 14 fewer specialist visits (adjusted $p<0.01$ ) and 9 fewer radiology tests (adjusted $p=0.01$ ). There were no significant differences in rates of primary care visits, laboratory tests, emergency department visits, hospitalizations or readmissions.

Conclusions: Patients of primary care providers who used EHRs were less likely to have specialist visits and radiology tests than patients of primary care providers who did not use EHRs.

\section{Correspondence to:}

Rainu Kaushal, MD, MPH

Department of Healthcare Policy and Research

Weill Cornell Medical College

402 East 67th Street, New York, NY 10065

Phone: 646-962-8006

Fax: 646-962-0281

E-mail: rak2007@med.cornell.edu
Appl Clin Inform 2015; 6: 42-55

http://dx.doi.org/10.4338/ACI-2014-10-RA-0089

received: October 14, 2014

accepted: December 22, 2014

published: January 28, 2015

Citation: Kaushal R, Edwards A, Kern LM, with the HITEC Investigators. Association between electronic health records and health care utilization. Appl Clin Inf 2015; 6: 42-55

http://dx.doi.org/10.4338/ACl-2014-10-RA-0089 


\section{Background}

Reducing the high cost of health care in the United States is an urgent policy objective $[1,2]$. One important tool with the potential to control costs is the interoperable electronic health record (EHR). EHRs enable electronic storage of a patient's health information and facilitate communication with other electronic systems [3]. EHRs also enable computerized clinical decision support in the form of alerts and reminders that can shape decision-making in real time and enable population management [4]. The federal government is providing approximately $\$ 20$ billion in incentives to providers for the "meaningful use" of interoperable EHRs to improve the quality, safety, and efficiency of care [5]. Several states have also made significant investments, particularly New York State with $\$ 880$ million allocated to date [6].

The actual effects of EHRs on health care costs are not well understood [7-9]. EHRs could decrease costs by: reducing adverse drug events through clinical decision support for prescribing, decreasing redundant testing by providing greater access to existing clinical data, saving time by avoiding the search for paper records, and preventing the need for emergency department visits or admissions through improved care coordination [10-12].

Alternatively, EHRs may increase costs. EHRs may decrease productivity through time-consuming documentation activities, increase the number of laboratory or radiology tests by making them easier to order, or decrease the amount of time spent with a patient, thereby leading to additional visits [13]. EHRs may enable appropriate increases in capture of revenue through more complete and accurate billing codes [14] or inappropriate increases through up-coding [15].

Thus, empirical evidence is critical for understanding the actual economic effects of EHRs. Previous studies have included return-on-investment analyses for office practices implementing systems [16-18] and system-wide savings before-and-after implementation in a single hospital or integrated delivery system [19-22]. Less is known about the effects of EHRs on health care utilization from the payer or societal perspective, especially in typical, multi-payer, small practice communitybased settings.

\section{Objective}

Our objective was to measure any association between adoption of EHRs and health care utilization - including potential shifts in costs across different types of health care utilization - for patients cared for by primary care providers in a multi-payer community.

\section{Methods}

\subsection{Overview}

We conducted a longitudinal cohort study of EHRs and health care utilization among primary care physicians in the Hudson Valley region of New York in 2008-2009. The Institutional Review Boards of Weill Cornell Medical College and Kingston Hospital approved the protocol. The study was registered with the National Institutes of Health Clinical Trials Registry (NCT00793065).

\subsection{Setting and Context}

The Hudson Valley is comprised of seven counties immediately north of New York City. This study took place in the context of an initiative led by THINC (Taconic Health Information Network and Community), a non-profit organization that convenes stakeholders to improve health care quality in the Hudson Valley [23]. THINC's efforts were supported by two grants from the New York State Department of Health: a \$5,000,000 grant in 2006 to support EHR licenses for physicians in the community and a $\$ 175,000$ grant in 2007 to convene health plans for a pay-for-performance program $[24,25]$. 


\subsection{Participants}

We included all general internists and family medicine physicians who were members of the Taconic Independent Practice Association (IPA), a not-for-profit organization [26]. The Taconic IPA includes approximately $50 \%$ of the physicians in the Hudson Valley. We also included non-member physicians who volunteered for THINC's initiative.

Of all providers in the Taconic IPA database in 2008, we restricted the study to primary care physicians (general internists and family medicine physicians) practicing in the seven counties of the Hudson Valley who had any patients with utilization data in the aggregated claims (described below). We then required a minimum number of patients per physician, in order to maximize the reliability of our estimates of utilization. Previous work suggested that physicians would each need $\geq 100$ patients with diabetes, in order for utilization profiles to have a reliability of $\geq 0.80$ [27]. Because patients in this study reflected the full spectrum of health states and not just diabetes, the patients in this study may use less health care than those in the diabetes study. Thus, we chose a minimum panel size of 200 patients. We further required that physicians have at least 200 patients per year, in 2008 and in 2009.

\subsection{Data}

\subsubsection{EHR status}

We used data that the IPA had collected in April 2008, regarding whether physicians had adopted an EHR or not. The IPA had previously formed MedAllies, a company that facilitates EHR implementation [28]. If physicians were known to MedAllies through direct observation as having implemented an EHR, they were classified as physicians using EHRs. Implementation was a process through which providers changed from using paper records to using EHRs for the primary documentation and delivery of clinical care. If physicians' EHR status was unknown, the IPA surveyed them by phone and classified them based on self-report. EHR status was updated in 2009. Practice management systems were specifically not considered EHRs. The community used at least 5 different major EHR vendor products, all of which included computerized clinical decision support. Data on actual usage were not available.

\subsubsection{Physician Characteristics}

We used seven other physician characteristics obtained by the IPA in 2008: age, gender, degree (MD vs. DO), specialty, county, practice size (the number of primary care physicians in the practice, including the participant), and adoption of a practice management system. Informed by Census data, we classified counties as rural vs. urban/suburban. Practice size was updated in 2009.

\subsubsection{Health Care Utilization}

Six health plans (three national commercial plans, Aetna, United and Empire; two regional commercial plans, MVP Healthcare and Capital District Physicians' Health Plan; and one regional Medicaid HMO, Hudson Health Plan) participated in the initiative. Five of the six health plans submitted claims data for calendar years 2008 and 2009 to a third-party aggregator, which ensured completeness and adherence to standardized specifications.

The data aggregator attributed each claim to a patient and then each patient to a primary care physician, using attribution logic ( Appendix 1). All of the patient's health care utilization was then assigned to the primary care physician to whom the patient was attributed, regardless of who ordered the health care services. In this way, primary care physicians were considered responsible for care coordination for their patients and thus for services ordered by other providers. We considered seven utilization outcomes: primary care visits, specialist visits, radiology and other diagnostic tests, laboratory tests, emergency department visits, hospital admissions, and 30-day all-cause readmissions. We considered these different outcomes specifically to capture any shifts across different types of care. Data were provided to us aggregated at the level of the physician. 


\subsubsection{Additional Physician Characteristics}

The data aggregator generated three additional physician characteristics for 2008 and, separately, for 2009: the total number of patients attributed to that physician (panel size), case mix, and plan mix. Case mix was derived using DxCG software [29-31]. Plan mix was a series of five physician-level variables, one for each health plan, which expressed the proportion of the physician's patients in the dataset covered by each health plan.

\subsection{Statistical Analysis}

We divided the sample into two study groups, based on chart type in 2008: those who had adopted EHRs and those using paper records. (We subsequently conducted a sensitivity analysis, described below, that considered chart type in 2009.) We compared the characteristics of the study groups, using chi-squared tests for categorical variables and t-tests for continuous variables, except for the comparison for practice size, for which we used a Wilcoxon rank-sum test, due to the non-normal distribution. Panel size was log-transformed due to skewness.

We created seven different regression models, one for each utilization outcome. We used negative binomial regression, because each utilization outcome is non-negative, positively skewed, and overdispersed $[32,33]$. For hospital readmissions, we used zero-inflated negative binomial regression, because this outcome has a larger than expected number of zero counts, in addition to having the other characteristics above [32]. We generated cluster robust standard errors to adjust for repeated measures within physicians over time.

In each of the seven models, the independent variables were: study group, year (2008 or 2009), and the interaction of study group and year. The dependent variable was the given utilization outcome, expressed as a rate (with panel size as the denominator). The models all adjusted for the same set of potential confounders: those physician characteristics that were associated with study group in bivariate analyses at baseline $(\mathrm{p}<0.20)$. All models allowed practice size, case mix, and plan mix to vary over time (if selected for the multivariate model); other co-variates were fixed at baseline levels.

We calculated relative and absolute differences in utilization across study groups and over time. We expressed relative differences as incidence rate ratios, with 95\% confidence intervals and p-values. The absolute utilization rates were calculated from the observed rate per 100 patients for each provider averaged across providers within study group and within each year. Using the coefficients from the regression models, we calculated the mean differences in rates over time and the difference-in-differences between study groups over time.

The base case models, described above, were consistent with an intention-to-treat approach, in which chart type at baseline was assumed to be constant over time. We conducted a sensitivity analysis excluding those physicians who changed chart type over time. The number of physicians who changed chart type was not large enough to allow analysis of them as a separate group $(\mathrm{N}=26)$.

We conducted a second, separate sensitivity analysis, excluding the 65 physicians, all from the EHR group, who worked in practices that underwent transformation into Patient-Centered Medical Homes in 2009 [34]. These practices were recognized late in 2009, so it is unlikely that health care utilization patterns in 2009 would reflect any effects of the PCMH, but we conducted the sensitivity analysis to confirm this.

We considered p-values $\leq 0.05$ to be statistically significant. We used SAS (version 9.3; Cary, NC) for t-tests and chi-squared tests and STATA (version 12; College Station, TX) for regression.

\section{Results}

\subsection{Study Sample}

We identified a total of 577 general internists and family physicians who were members of the Taconic IPA, practicing in the Hudson Valley, and had any patients with utilization data in the aggregated claims dataset in 2008 ( Figure 1). We found that nearly two-thirds of these physicians $(\mathrm{N}=$ $366,63 \%)$ each had at least 200 patients and together cared for the large majority (91\%) of patients 
in the community. Almost all of these physicians $(\mathrm{N}=328,90 \%)$ also had at least 200 patients in 2009. The aggregated claims reflected care by these physicians for 223,772 unique patients. Of the 328 physicians, approximately half $(\mathrm{N}=170,54 \%)$ were using EHRs and half $(\mathrm{N}=158,46 \%)$ were using paper records in 2008.

For the sensitivity analysis, only 26 (8\%) of the 328 physicians changed chart type over time. Twenty-four physicians who were using paper in 2008 changed to EHRs by 2009, and two physicians who were using EHRs in 2008 reverted to paper by 2009.

\subsection{Physician Characteristics}

Nearly one-third of physicians (31\%) were female ( $>$ Table 1$)$. The average physician was 50 years old. Most (88\%) had MD degrees. Approximately half were general internists (56\%) and half family physicians (44\%). One in five (21\%) worked in a rural county. The median practice size was four primary care physicians, and the average number of patients per physician in this dataset was 521 . The average case mix score was 3.4, indicating a slightly sicker patient population than the national average, which is 1.0. The average physician had patients in all five health plans.

Compared to physicians using paper records, physicians using EHRs were younger (47 years vs. 53 years, $\mathrm{p}<0.0001)$, more likely to have DO degrees $(15 \%$ vs. $8 \%, \mathrm{p}=0.03)$, more likely to be in larger practices (24 physicians vs. 2 physicians, $\mathrm{p}<0.0001$ ), and more likely to have an electronic practice management system $(76 \%$ vs. $50 \%, \mathrm{p}<0.0001)$. There were no significant differences in physician gender, specialty, county, panel size, case mix or plan mix.

\subsection{Relative and Absolute Differences}

We found that patients whose primary care physicians used EHRs had significantly fewer specialist visits and significantly fewer radiology and other diagnostic tests, compared to patients whose physicians used paper records. The adjusted relative reduction in specialist visits was $4 \%(p=0.002)$ and the adjusted relative reduction in radiology and other diagnostic tests was also 4\% ( $\mathrm{p}=0.01$; $>$ Table 2). For every 100 patients whose primary care physician used an EHR, there were 14 fewer specialist visits per year and 9 fewer radiology and other diagnostic tests per year, compared to patients whose primary care physician used a paper record ( $>$ Table 3 ).

There was a trend toward more primary care visits in the EHR group. The adjusted relative increase in primary care visits was $2 \%(\mathrm{p}=0.08$, Table 2$)$. This is equivalent to an absolute increase in 7 primary care visits per 100 patients per year, although this was not statistically significant ( Table 3).

There were no differences between study groups for the other outcomes: laboratory tests, emergency department visits, hospital admissions, or 30-day all-cause readmissions.

When we excluded the small number of physicians who changed chart type, the adjusted results persisted. For every 100 patients whose primary care physician used an EHR, there were 18 fewer specialist visits per year $(\mathrm{p}<0.001)$ and 10 fewer radiology and other diagnostic tests per year $(\mathrm{p}=$ 0.01 ), compared to patients whose primary care physician used a paper record.

When we excluded the physicians whose practices transformed into PCMHs, the adjusted results persisted. For every 100 patients whose primary care physician used an EHR, there were 13 fewer specialist visits per year $(\mathrm{p}<0.01)$ and 14 fewer radiology and other diagnostic tests per year $(\mathrm{p}<$ 0.001 ), compared to patients whose primary care physician used a paper record.

\section{Discussion}

In this community-based study of predominantly small practices with commercially available EHRs, we found that usage of EHRs, compared to paper records, was associated with 14 fewer specialist visits and 9 fewer radiology tests for every 100 patients. We found a trend toward more primary care visits for patients of physicians using EHRs but no differences in other outcomes.

EHRs might have enhanced primary care physicians' access to clinical data, including prior radiology tests and consultations with other physicians, as well as improved medical decision-making, 
thereby decreasing the need for specialist consultation and additional radiology images. The change in radiology tests is consistent with a recent study, which aggregated patients at the level of the community and found a modest association between outpatient EHRs and lower radiology costs [35].

This study did not find an association between EHRs and rates of laboratory tests. Prior work on laboratory tests has come mostly from the inpatient setting and has used specific, often custom-built reminders to encourage cancellation of apparently redundant laboratory tests [36]. Our study suggests that more decision support may be needed to reduce laboratory test ordering with EHRs in the outpatient setting.

This study followed physicians for a total of two years and did not find a difference in emergency department visits, admissions or readmissions. It is possible that these outcomes require longer follow-up periods and/or larger sample sizes, because these events are relatively rare and more multifactorial in etiology.

Few previous studies have measured the effects of EHRs on health care utilization in communitybased settings [37]. Most previous studies have been based on expert opinion or return-on-investment analyses [22]. Others have come from integrated delivery systems [19-21]. This study builds on the literature by measuring health care utilization - including potential shifts across seven types of utilization - in a multi-payer community with fee-for-service reimbursement and generally small office practices.

This study also contributes to the literature by evaluating the effects of commercially available EHRs. Most previous work on the effects of EHRs has come from a few hospitals and integrated delivery systems that have iteratively refined home-grown EHR products over decades [38, 39]. Many providers are now using or transitioning to commercial EHRs, [39] even though the effects of these off-the-shelf products are less clear.

This study took place prior to the implementation of the federal EHR Incentive ("Meaningful Use") Program [40]. At the time of this study, approximately $50 \%$ of the primary care physicians in the community were using EHRs, and the national rate of EHR adoption among primary care physicians has since surpassed that [41]. Thus, this study captures the natural experiment of EHRs' effects before they become too widespread to isolate.

This study has several limitations. First, this study does not capture actual usage of EHRs (that is, the intensity with which the primary care provider used electronic functionalities). Future studies should delve deeper into which types of usage drive medical decision making [42, 43]. Second, this study measures utilization but not cost. Our research dataset did not contain charge data, so we were not able to calculate savings per se. There are also few statistics nationally on the "average" specialist visit, or the "average" radiology test, so we could not convert our findings to dollars. Our dataset also did not contain claim-level CPT codes, so we were not able to capture the intensity of any encounter and thus cannot comment on the presence or absence of up-coding. Third, our study was not randomized, and we cannot exclude unmeasured confounders. However, given the national policy environment, there will probably never be a randomized controlled trial of EHRs, leaving observational studies as the best possible source of data on this topic. Fourth, we did not have information on the prevalence of EHRs among specialist physicians in this community, which might have affected referral rates, although we suspect that the rate of EHR adoption among specialists was lower than that among primary care physicians, based on national trends [44]. Finally, we studied several hundred physicians and many of their commercially insured patients from one community with feefor-service reimbursement. Additional studies are needed to confirm the generalizability of these results in other communities and with other reimbursement models.

The implication of this work is that EHRs may indeed change patterns of health care utilization. They may enable primary care physicians to order fewer consultations with specialists and fewer radiology tests, thus reducing health care utilization. However, EHRs alone are not likely to be enough to bend the national cost curve. Reducing the more expensive types of utilization, such as emergency department visits and hospitalizations, may require more extensive health care transformation, including practice redesign and payment reform. These types of innovations are enabled by - and indeed require - EHRs. Thus, the complete economic impact of EHRs may not be found in a study of EHRs alone. 


\section{Conclusions}

In summary, we found that community-based primary care physicians who used EHRs were less likely to refer their patients to specialists and less likely to order radiology tests, compared to their peers who used paper records. This finding was observed in a multi-payer, multi-provider community that may be highly generalizable to other communities across the country.

\section{Clinical Relevance}

This study suggests that EHRs may indeed change patterns of health care utilization. They may enable primary care physicians to order fewer consultations and fewer radiology tests, thus reducing health care utilization. Reducing the more expensive types of utilization, such as emergency department visits and hospitalizations, may require more extensive health care transformation, including practice redesign and payment reform.

\section{Acknowledgements}

This work was supported by the New York State Department of Health (contract \#C023699). The authors thank A. John Blair III, MD, President of the Taconic IPA and CEO of MedAllies, and Susan Stuard, MBA, Executive Director of THINC, for providing access to data.

\section{Human Subject Research Approval}

The Institutional Review Boards of Weill Cornell Medical College and Kingston Hospital approved the protocol. The study was registered with the National Institutes of Health Clinical Trials Registry (NCT00793065).

\section{Conflict Of Interest Statement}

The authors have no financial conflicts of interest to disclose. 


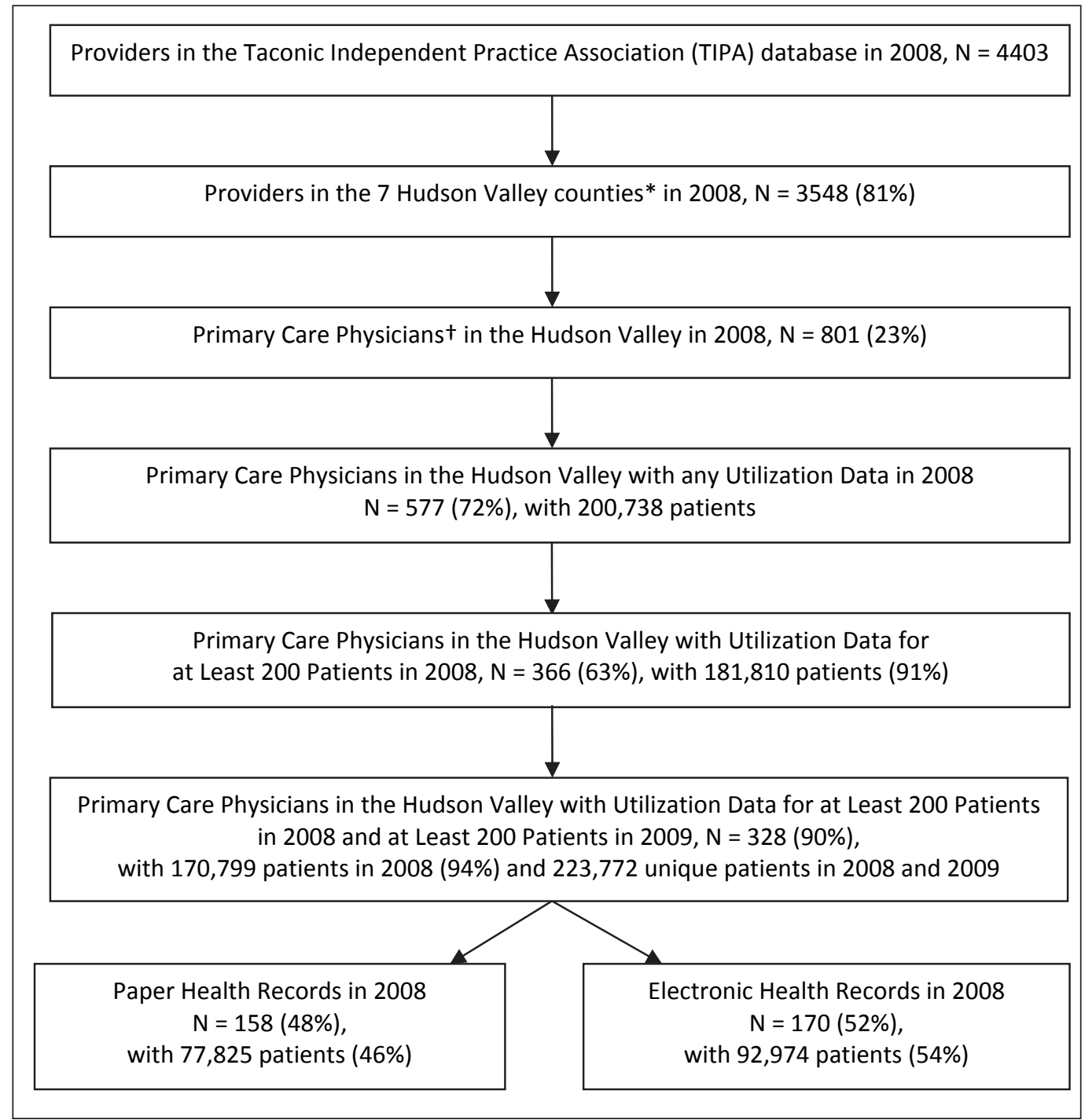

Fig. 1 Derivation of the study sample ( ${ }^{*}$ The 7 Hudson Valley counties were: Dutchess, Orange, Putnam, Rockland, Sullivan, Ulster and Westchester. † Primary Care Providers were MDs or DOs in General Internal Medicine or Family Medicine). 
Table 1 Characteristics of primary care physicians at baseline (in 2008) and stratified by use of paper vs. electronic health records (EHRs)

\begin{tabular}{|c|c|c|c|c|}
\hline Physician Characteristic & $\begin{array}{l}\text { Total } \\
N=328\end{array}$ & $\begin{array}{l}\text { Paper } \\
N=158\end{array}$ & $\begin{array}{l}\text { EHR } \\
N=170\end{array}$ & p-value* \\
\hline Gender, female: N (\%) & $101(31)$ & $41(26)$ & $60(35)$ & 0.07 \\
\hline Age, years (as of 12/31/2008): Mean (SD) & $50(10)$ & $53(9)$ & $47(9)$ & $<0.0001$ \\
\hline Degree, MD (vs. DO): N (\%) & $290(88)$ & $146(92)$ & $144(85)$ & 0.03 \\
\hline $\begin{array}{l}\text { Specialty: N }(\%) \\
\text { - General Internal Medicine } \\
\text { - Family Medicine }\end{array}$ & $\begin{array}{l}185(56) \\
143(44)\end{array}$ & $\begin{array}{l}91(58) \\
67(42)\end{array}$ & $\begin{array}{l}94(55) \\
76(45)\end{array}$ & 0.67 \\
\hline Rural county: N (\%) & $70(21)$ & $32(20)$ & $38(22)$ & 0.64 \\
\hline Practice sizet: Mean (SD) & $14(18)$ & $2(3)$ & $24(19)$ & $<0.0001$ \\
\hline Panel size: Mean (SD) & $521(302)$ & $493(250)$ & $547(342)$ & 0.22 \\
\hline Case mix: Mean (SD) & $3.4(1.3)$ & $3.4(1.2)$ & $3.4(1.3)$ & $>0.99$ \\
\hline $\begin{array}{l}\text { Plan mix: Mean \% of panel covered by each plan } \\
\text { Plan A } \\
\text { - Plan B } \\
\text { Plan C } \\
\text { - Plan D } \\
\text { - Plan E }\end{array}$ & $\begin{array}{r}28 \\
33 \\
3 \\
9 \\
27\end{array}$ & $\begin{array}{r}25 \\
38 \\
4 \\
4 \\
29\end{array}$ & $\begin{array}{r}32 \\
28 \\
3 \\
13 \\
24\end{array}$ & 0.10 \\
\hline Electronic practice management system: N (\%) & $209(64)$ & $79(50)$ & $130(76)$ & $<0.0001$ \\
\hline
\end{tabular}

* P-values were generated with chi-squared tests for categorical variables and t-tests for continuous variables, except for the $p$-value for practice size, which was generated with a Wilcoxon rank-sum test, due to the non-normal distribution of practice size. Panel size was log-transformed prior to applying the t-test. Age was missing for 1 provider.

† Practice size was defined as the number of general internists, family physicians and pediatricians in the practice, including the participant. 
Table 2 Relative differences in rates of health care utilization by type of health record (EHR vs. paper) over time $(\mathrm{N}=328)$

\begin{tabular}{|c|c|c|c|c|}
\hline \multirow[t]{3}{*}{ Utilization Measure } & \multicolumn{4}{|c|}{ Incidence Rate Ratios (IRRs)* } \\
\hline & \multicolumn{2}{|l|}{ Unadjusted } & \multicolumn{2}{|l|}{ Adjusted } \\
\hline & IRR (95\% CI) & $p$-value & $\operatorname{IRR}^{\dagger}(95 \% \mathrm{CI})$ & $p$-value \\
\hline Primary Care Visits & $1.002(0.98,1.02)$ & 0.85 & $1.02(0.997,1.05)$ & 0.08 \\
\hline Specialist Visits & $0.99(0.97,1.01)$ & 0.26 & $0.96(0.93,0.98)$ & 0.002 \\
\hline $\begin{array}{l}\text { Radiology and Other Diagnostic } \\
\text { Tests }\end{array}$ & $0.97(0.94,1.01)$ & 0.10 & $0.96(0.92,0.99)$ & 0.01 \\
\hline Laboratory Tests & $0.98(0.95,1.01)$ & 0.29 & $0.98(0.95,1.02)$ & 0.29 \\
\hline Emergency Department Visits & $1.08(1.01,1.14)$ & 0.02 & $1.04(0.98,1.10)$ & 0.21 \\
\hline Hospital Admissions & $1.05(0.95,1.16)$ & 0.38 & $1.02(0.93,1.11)$ & 0.73 \\
\hline Hospital Readmissions & $1.02(0.82,1.26)$ & 0.88 & $0.97(0.79,1.19)$ & 0.74 \\
\hline
\end{tabular}

*The incidence rate ratios (IRRs) are for the interaction between type of health record (EHR vs. paper) and time (2009 vs. 2008). IRRs were generated from negative binomial regression models, except for the IRRs for hospital readmissions, which were generated from zero-inflated negative binomial regression models, with admissions and case mix as predictors of inflation.

${ }^{\dagger}$ All multivariable models adjusted for gender, age, degree, practice size, plan mix, and practice management system, as these were significant in bivariate models $(p<0.20)$. Multivariable models did not adjust for panel size, because panel size was incorporated into the denominator of the utilization rate (e.g. events per 100 patients). Of the 328 physicians in the study, one was excluded from the multivariate model due to missing data for age. 
Table 3 Absolute differences in rates of health care utilization by type of health record (paper vs. EHR) over time $(\mathrm{N}=328)$

\begin{tabular}{|c|c|c|c|c|c|}
\hline \multirow[t]{2}{*}{ Utilization Measure } & \multicolumn{2}{|c|}{$\begin{array}{l}\text { Observed Mean Rates (SD) } \\
\text { per } 100 \text { Patients }\end{array}$} & \multicolumn{3}{|c|}{$\begin{array}{l}\text { Estimated Mean Differences in Rates } \\
(95 \% \mathrm{Cl}) \text { per } 100 \text { Patients }\end{array}$} \\
\hline & 2008 & 2009 & $\begin{array}{l}\text { Observed } \\
\text { Difference } \\
2009-2008^{*}\end{array}$ & $\begin{array}{l}\text { Estimated } \\
\text { Difference } \\
2009-2008^{\dagger}\end{array}$ & $\begin{array}{l}\text { Estimated } \\
\text { Difference in } \\
\text { Differences }^{\dagger}\end{array}$ \\
\hline $\begin{array}{l}\text { Primary Care Visits } \\
\text { - Paper } \\
\text { - EHR }\end{array}$ & $\begin{array}{l}314.8(95.0) \\
286.4(58.0)\end{array}$ & $\begin{array}{l}322.8(100.7) \\
294.2(68.3)\end{array}$ & $\begin{array}{l}8.0(3.0,13.0) \\
7.8(3.5,12.3)\end{array}$ & $\begin{array}{l}9.7(4.2,15.2) \\
16.6(10.2,23.1)\end{array}$ & $6.7(-0.9,14.4)$ \\
\hline $\begin{array}{l}\text { Specialist Visits } \\
\text { - Paper } \\
\text { - EHR }\end{array}$ & $\begin{array}{l}338.0(95.9) \\
332.2(102.4)\end{array}$ & $\begin{array}{l}357.2(100.6) \\
346.9(106.0)\end{array}$ & $\begin{array}{l}19.2(14.0,24.3) \\
14.7(9.7,19.7)\end{array}$ & $\begin{array}{l}18.5(11.4,25.6) \\
3.4(-3.9,10.7)\end{array}$ & $-14.4(-23.6,-5.2)$ \\
\hline $\begin{array}{l}\text { Radiology and } \\
\text { Other Diagnostic Tests } \\
\text { - Paper } \\
\text { - EHR }\end{array}$ & $\begin{array}{l}219.9(56.5) \\
209.7(61.9)\end{array}$ & $\begin{array}{l}219.8(53.1) \\
204.0(55.9)\end{array}$ & $\begin{array}{l}-0.1(-4.8,4.4) \\
-5.7(-10.7,-0.7)\end{array}$ & $\begin{array}{l}2.8(-2.5,8.2) \\
-6.5(-12.1,-0.9)\end{array}$ & $-9.2(-16.3,-2.2)$ \\
\hline $\begin{array}{l}\text { Laboratory Tests } \\
\text { - Paper } \\
\text { - EHR }\end{array}$ & $\begin{array}{l}1270.3(438.7) \\
1258.6(392.7)\end{array}$ & $\begin{array}{l}1350.2(466.5) \\
1314.5(387.1)\end{array}$ & $\begin{array}{l}79.9(51.0,108.8) \\
55.9(25.7,86.2)\end{array}$ & $\begin{array}{l}100.8(71.0,130.6) \\
74.2(38.5,109.9)\end{array}$ & $-23.3(-66.3,19.7)$ \\
\hline $\begin{array}{l}\text { Emergency Department } \\
\text { Visits } \\
\text { - Paper } \\
\text { - EHR }\end{array}$ & $\begin{array}{l}18.8(12.3) \\
23.5(14.6)\end{array}$ & $\begin{array}{l}18.8(13.1) \\
25.3(18.8)\end{array}$ & $\begin{array}{l}0.0(-0.8,0.8) \\
1.8(0.6,3.0)\end{array}$ & $\begin{array}{l}0.2(-0.6,1.0) \\
0.9(0.2,1.7)\end{array}$ & $0.7(-0.4,1.8)$ \\
\hline $\begin{array}{l}\text { Hospital Admissions } \\
\text { - Paper } \\
\text { - EHR }\end{array}$ & $\begin{array}{l}7.7(4.3) \\
8.8(4.4)\end{array}$ & $\begin{array}{l}7.0(4.3) \\
8.3(4.5)\end{array}$ & $\begin{array}{l}-0.7(-1.2,-0.2) \\
-0.5(-1.0,0.2)\end{array}$ & $\begin{array}{l}-0.3(-0.9,0.2) \\
-0.2(-0.7,0.3)\end{array}$ & $0.1(-0.6,0.8)$ \\
\hline $\begin{array}{l}\text { Hospital Readmissions }{ }^{\ddagger} \\
\text { - Paper } \\
\text { - EHR }\end{array}$ & $\begin{array}{l}1.7(1.5) \\
1.8(1.8)\end{array}$ & $\begin{array}{l}1.4(1.4) \\
1.6(1.8)\end{array}$ & $\begin{array}{l}-0.3 \\
-0.2\end{array}$ & & \\
\hline
\end{tabular}

*Observed absolute mean differences with $95 \%$ confidence intervals were calculated using negative binomial regression, adjusting for clustering by provider but not adjusting for co-variates.

${ }^{\dagger}$ Estimated absolute mean differences with $95 \%$ confidence intervals were calculated using negative binomial regression, adjusting for clustering by provider and adjusting for co-variates (gender, age, degree, practice size, plan mix, and practice management system). Of the 328 physicians in the study, one was excluded from the multivariate model due to missing data for age.

${ }^{\ddagger}$ The model for hospital readmissions was generated with zero-inflated negative binomial regression, with admissions and health plan as the predictors causing inflation. Because readmissions were so rare, it was not possible to generate stable estimates of the $95 \%$ confidence intervals for observed differences, nor was it possible to generate stable estimates of the estimated differences. 


\section{References}

1. Berwick DM, Hackbarth AD. Eliminating waste in US health care. J Am Med Inform Assoc 2012; 307(14): 1513-1516. PubMed PMID: 22419800. Epub 2012/03/16.

2. Keehan SP, Sisko AM, Truffer CJ, Poisal JA, Cuckler GA, Madison AJ, et al. National health spending projections through 2020: economic recovery and reform drive faster spending growth. Health Aff (Millwood) 2011; 30(8): 1594-1605. PubMed PMID: 21798885. Epub 2011/07/30.

3. Halamka JD. Health information technology: shall we wait for the evidence? Ann Intern Med 2006; 144(10): 775-776. PubMed PMID: 16702595.

4. Garg AX, Adhikari NK, McDonald H, Rosas-Arellano MP, Devereaux PJ, Beyene J, et al. Effects of computerized clinical decision support systems on practitioner performance and patient outcomes: a systematic review. J Am Med Inform Assoc 2005; 293(10): 1223-1238. PubMed PMID: 15755945. Epub 2005/03/10.

5. Steinbrook R. Health care and the American Recovery and Reinvestment Act. N Engl J Med 2009; 360(11): 1057-1060. PubMed PMID: 19224738. Epub 2009/02/20.

6. New York State Department of Health. Office of Health Information Technology Transformation. (Accessed December 12, 1014 http://www.health.state.ny.us/technology.)

7. Kellermann AL, Jones SS. What it will take to achieve the as-yet-unfulfilled promises of health information technology. Health Aff (Millwood) 2013; 32(1): 63-68. PubMed PMID: 23297272. Epub 2013/01/09.

8. Low AFH, Phillips AB, Ancker JS, Patel AR, Kern LM, Kaushal R. Financial effects of health information technology: a systematic review. The American journal of managed care 2013; 19(10 Spec No): SP369-SP376. PubMed PMID: 24511891.

9. Congressional Budget Office. Evidence on the costs and benefits of health information technology; 2008. (Accessed December 12, 2014, at www.cbo.gov/sites/default/files/cbofiles/ftpdocs/91xx/ doc9168/05-20-healthit.pdf.)

10. Bates DW, Gawande AA. Improving safety with information technology. N Engl J Med 2003; 348(25): 2526-2534. PubMed PMID: 12815139.

11. Kern LM, Barron Y, Dhopeshwarkar RV, Edwards A, Kaushal R. Electronic health records and ambulatory quality of care. J Gen Intern Med 2013; 28(4): 496-503. PubMed PMID: 23054927. Epub 2012/10/12.

12. Tierney WM, McDonald CJ, Martin DK, Rogers MP. Computerized display of past test results. Effect on outpatient testing. Ann Intern Med 1987; 107(4): 569-574. PubMed PMID: 3631792.

13. Poissant L, Pereira J, Tamblyn R, Kawasumi Y. The impact of electronic health records on time efficiency of physicians and nurses: a systematic review. J Am Med Inform Assoc 2005; 12(5): 505-516. PubMed PMID: 15905487. Epub 2005/05/21.

14. Cheriff AD, Kapur AG, Qiu M, Cole CL. Physician productivity and the ambulatory EHR in a large academic multi-specialty physician group. Int J Med Inform 2010; 79(7): 492-500. PubMed PMID: 20478738. Epub 2010/05/19.

15. Abelson R, Creswell J, Palmer G. Medicare bills rise as records turn electronic. New York Times. September 22, 2012; Sect. A1.

16. Grieger DL, Cohen SH, Krusch DA. A pilot study to document the return on investment for implementing an ambulatory electronic health record at an academic medical center. J Am Coll Surg 2007; 205(1): 89-96. PubMed PMID: 17617337. Epub 2007/07/10.

17. Miller RH, West C, Brown TM, Sim I, Ganchoff C. The value of electronic health records in solo or small group practices. Health Aff (Millwood) 2005; 24(5): 1127-1137. PubMed PMID: 16162555. Epub 2005/09/16.

18. Welch WP, Bazarko D, Ritten K, Burgess Y, Harmon R, Sandy LG. Electronic health records in four community physician practices: impact on quality and cost of care. J Am Med Inform Assoc 2007; 14(3): 320-328. PubMed PMID: 17329734. Epub 2007/03/03.

19. Byrne CM, Mercincavage LM, Pan EC, Vincent AG, Johnston DS, Middleton B. The value from investments in health information technology at the U.S. Department of Veterans Affairs. Health Aff (Millwood) 2010; 29(4): 629-638. PubMed PMID: 20368592. Epub 2010/04/07.

20. Chen C, Garrido T, Chock D, Okawa G, Liang L. The Kaiser Permanente Electronic Health Record: transforming and streamlining modalities of care. Health Aff (Millwood) 2009; 28(2): 323-333. PubMed PMID: 19275987. Epub 2009/03/12.

21. Garrido T, Jamieson L, Zhou Y, Wiesenthal A, Liang L. Effect of electronic health records in ambulatory care: retrospective, serial, cross sectional study. BMJ 2005; 330(7491): 581. PubMed PMID: 15760999. Epub 2005/03/12. 
22. Wang SJ, Middleton B, Prosser LA, Bardon CG, Spurr CD, Carchidi PJ, et al. A cost-benefit analysis of electronic medical records in primary care. Am J Med 2003; 114(5): 397-403. PubMed PMID: 12714130. Epub 2003/04/26.

23.THINC: Taconic Health Information Network and Community. (Accessed December 12, 2014, at www.thinc.org

24. New York State Department of Health. Health Information Technology (HIT) Grants - HEAL NY Phase 1. (Accessed December 12, 2014, at www.health.ny.gov/technology/awards/.)

25. New York State. New York State provides $\$ 9.5$ million for incentive program to promote high-quality, more affordable health care. 2007. (Accessed December 12, 2014, http://www.state.ny.us/governor/press/0913071.html

26. Taconic IPA. (Accessed December 12, 2014, at www.taconicipa.com.)

27. Hofer TP, Hayward RA, Greenfield S, Wagner EH, Kaplan SH, Manning WG. The unreliability of individual physician "report cards" for assessing the costs and quality of care of a chronic disease. J Am Med Inform Assoc 1999; 281(22): 2098-2105. PubMed PMID: 10367820. Epub 1999/06/15.

28. MedAllies. (Accessed December 12, 2014, at www.medallies.com.)

29. Centers for Medicare and Medicaid Services. Medicare Advantage - Rates and Statistics - Risk Adjustment. (Accessed December 12, 2014, http://www.cms.gov/Medicare/Health-Plans/MedicareAdvtgSpecRa teStats/Risk-Adjustors.html.)

30. Verisk Health. DxCG Risk Analytics. (Accessed December 12, 2014, at www.veriskhealth.com/answers/ population-answers/dxcg-risk-analytics.)

31. Ash AS, Ellis RP, Pope GC, Ayanian JZ, Bates DW, Burstin H, et al. Using diagnoses to describe populations and predict costs. Health Care Financ Rev 2000; 21(3): 7-28. PubMed PMID: 11481769.

32.Long JS, Freese J. Regression models for categorical dependent variables using Stata, 2nd ed. College Station, TX: Stata Press; 2006.

33. McCullagh P, Nelder JA. Generalized linear models, 2nd ed. New York: Chapman and Hill; 1989.

34. National Committee for Quality Assurance. Standards and guidelines for Physician Practice Connections - Patient-Centered Medical Home (PPC-PCMH), 2008. (Accessed December 12, 2014 http://www.ncqa. org/Portals/0/Programs/Recognition/PCMH_Overview_Apr01.pdf.)

35. Adler-Milstein J, Salzberg C, Franz C, Orav EJ, Newhouse JP, Bates DW. Effect of electronic health records on health care costs: longitudinal comparative evidence from community practices. Ann Intern Med 2013; 159(2): 97-104. PubMed PMID: 23856682. Epub 2013/07/17.

36. Bates DW, Kuperman GJ, Rittenberg E, Teich JM, Fiskio J, Ma'luf N, et al. A randomized trial of a computer-based intervention to reduce utilization of redundant laboratory tests. Am J Med 1999; 106(2): 144-150. PubMed PMID: 10230742.

37. Goldzweig CL, Towfigh A, Maglione M, Shekelle PG. Costs and benefits of health information technology: new trends from the literature. Health Aff (Millwood) 2009; 28(2): w282-w293. PubMed PMID: 19174390. Epub 2009/01/29.

38. Chaudhry B, Wang J, Wu S, Maglione M, Mojica W, Roth E, et al. Systematic review: impact of health information technology on quality, efficiency, and costs of medical care. Ann Intern Med 2006; 144(10): 742-752. PubMed PMID: 16702590.

39. Classen DC, Bates DW. Finding the meaning in meaningful use. N Engl J Med 2011; 365(9): 855-858. PubMed PMID: 21879906. Epub 2011/09/02.

40. Blumenthal D. Launching HITECH. N Engl J Med 2010; 362(5): 382-385. PubMed PMID: 20042745. Epub 2010/01/01.

41.Jamoom E, Beatty P, Bercovitz A, Woodwell D, Palso K, Rechtsteiner E. Physician adoption of electronic health record systems: United States, 2011. NCHS data brief, no. 98. Hyattsville, MD: 2012.

42. Ancker JS, Kern LM, Edwards A, Nosal S, Stein DM, Hauser D, et al. How is the electronic health record being used? Use of EHR data to assess physician-level variability in technology use. J Am Med Inform Assoc 2014; 21(6): 1001-1008. PubMed PMID: 24914013.

43. Isaac T, Weissman JS, Davis RB, Massagli M, Cyrulik A, Sands DZ, et al. Overrides of medication alerts in ambulatory care. Arch Intern Med 2009; 169(3): 305-311. PubMed PMID: 19204222. Epub 2009/02/11.

44. Grinspan ZM, Banerjee S, Kaushal R, Kern LM. Physician specialty and variations in adoption of electronic health records. Applied Clinical Informatics 2013; 4(2): 225-240. PubMed PMID: 23874360. 


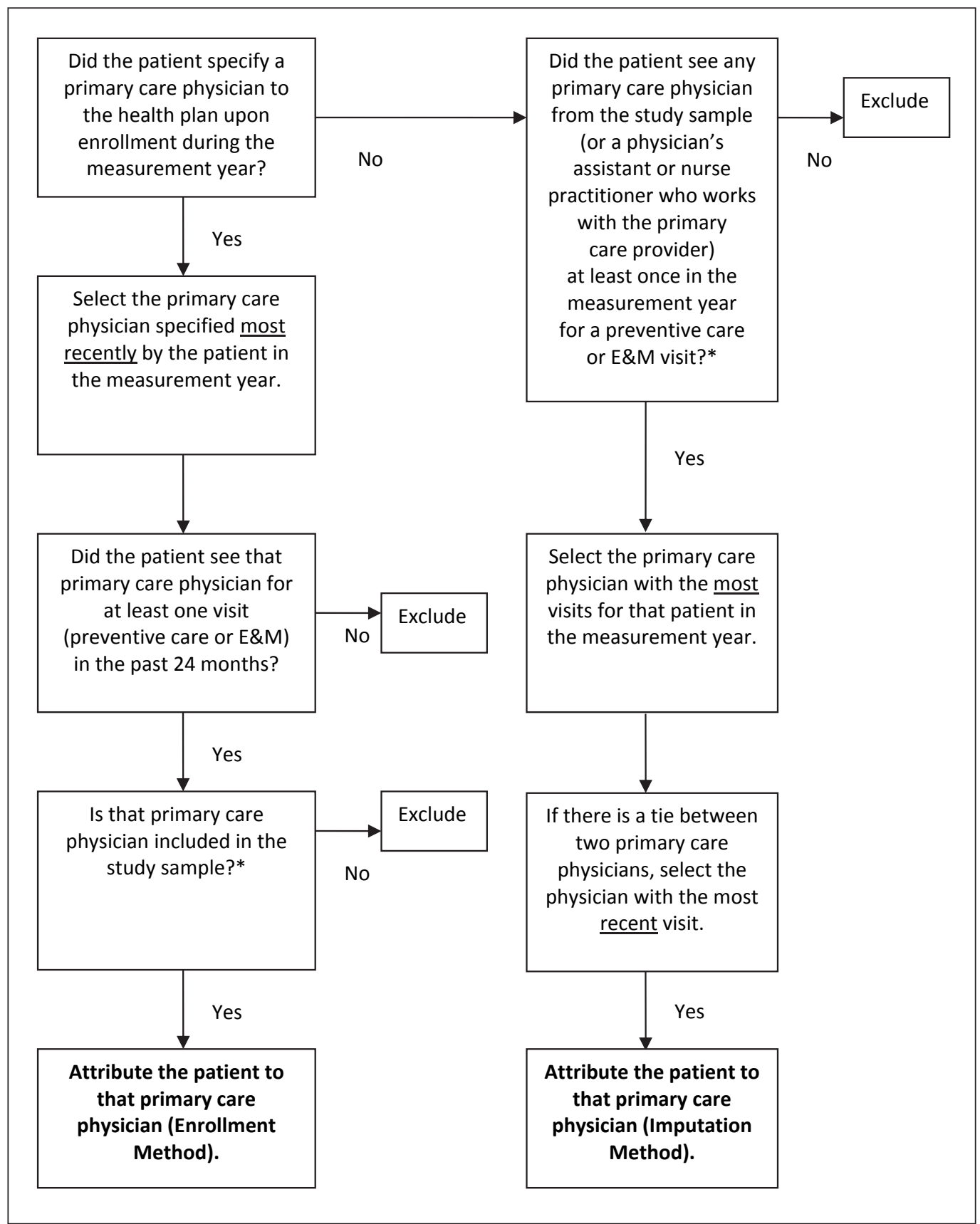

Appendix 1 Logic for attributing patients to primary care physicians (*see Figure 1 for a derivation of the study sample. "E \& M" = Evaluation and Management). 